\title{
Article \\ Nanostructured Hybrid Metal Mesh as Transparent Conducting Electrodes: Selection Criteria Verification in Perovskite Solar Cells
}

\author{
John Mohanraj ${ }^{1, * \mathbb{D}}$, Chetan R. Singh ${ }^{1}$, Tanaji P. Gujar ${ }^{1}$, C. David Heinrich ${ }^{1} \mathbb{D}$ and Mukundan Thelakkat ${ }^{1,2, * \mathbb{D}}$ \\ 1 Applied Functional Polymers, University of Bayreuth, 95440 Bayreuth, Germany; \\ chetan-raj.singh@uni-bayreuth.de (C.R.S.); tanaji.gujar@uni-bayreuth.de (T.P.G.); \\ David.heinrich@uni-bayreuth.de (C.D.H.) \\ 2 Bavarian Polymer Institute (BPI), University of Bayreuth, 95440 Bayreuth, Germany \\ * Correspondence: john.mohanraj@uni-bayreuth.de (J.M.); mukundan.thelakkat@uni-bayreuth.de (M.T.)
}

Citation: Mohanraj, J.; Singh, C.R.; Gujar, T.P.; Heinrich, C.D.; Thelakkat, M. Nanostructured Hybrid Metal Mesh as Transparent Conducting Electrodes: Selection Criteria Verification in Perovskite Solar Cells. Nanomaterials 2021, 11, 1783. https:// doi.org/10.3390/nano11071783

Academic Editor: Byungwoo Park

Received: 7 June 2021

Accepted: 7 July 2021

Published: 9 July 2021

Publisher's Note: MDPI stays neutral with regard to jurisdictional claims in published maps and institutional affiliations.

Copyright: (c) 2021 by the authors. Licensee MDPI, Basel, Switzerland. This article is an open access article distributed under the terms and conditions of the Creative Commons Attribution (CC BY) license (https:// creativecommons.org/licenses/by/ $4.0 /)$.

\begin{abstract}
Nanostructured metal mesh structures demonstrating excellent conductivity and high transparency are one of the promising transparent conducting electrode (TCE) alternatives for indium tin oxide (ITO). Often, these metal nanostructures are to be employed as hybrids along with a conducting filler layer to collect charge carriers from the network voids and to minimize current and voltage losses. The influence of filler layers on dictating the extent of such ohmic loss is complex. Here, we used a general numerical model to correlate the sheet resistance of the filler, lateral charge transport distance in network voids, metal mesh line width and ohmic losses in optoelectronic devices. To verify this correlation, we prepared gold or copper network electrodes with different line widths and different filler layers, and applied them as TCEs in perovskite solar cells. We show that the photovoltaic parameters scale with the hybrid metal network TCE properties and an Au-network or Cu-network with aluminum-doped zinc oxide (AZO) filler can replace ITO very well, validating our theoretical predictions. Thus, the proposed model could be employed to select an appropriate filler layer for a specific metal mesh electrode geometry and dimensions to overcome the possible ohmic losses in optoelectronic devices.
\end{abstract}

Keywords: metal mesh electrodes; conducting filler layer; ohmic losses; sheet resistance; transparent conducting electrode

\section{Introduction}

Recent technological developments transcending the vision of the Internet of Things (IoT) have created a huge global market for "smart" devices such as smart phones, televisions, tablets, watches and many more, which is forecast to grow exponentially over the next few years [1]. Naturally, this progress goes in parallel with the demand for electronic components used in smart devices and in particular, in energy conversion and storage applications. While renewable energy resources are considered for clean and sustainable energy production around the world, solar cells are among the potential technologies that significantly contribute toward the present global energy demands and is anticipated to grow further in the future [2,3]. Both in solar cells and in most of the smart devices containing transparent displays or touch panels, one of the inevitable device stacks is the transparent conducting electrode (TCE). To date, indium tin oxide (ITO) has been ubiquitously employed as TCE in applications requiring high transparency and low sheet resistance. However, with the ever growing demand for TCEs, the scarcity of indium coupled with its cost and energy inefficient production methods and its poor durability in flexible electronic applications prompt the search for appropriate ITO alternatives [4].

Many novel materials such as PEDOT:PSS [5,6], graphene [7], carbon nanotubes [8] and metal nanostructures [9] with low sheet resistance $(>1 \Omega / \square)$, high transmittance 
$(>80 \%)$ in the visible region and high durability have been investigated as TCEs in various optoelectronic applications. Among these, metal nanostructures, in particular, metal mesh electrodes, hold additional promising features like intrinsic high conductivity, transparency in the visible and infrared region, low haze, surface plasmonic effect, high flexibility, and versatile and cost effective preparation strategies, which are best suited for photovoltaic applications $[9,10]$. For example, Ag nanowires/mesh electrodes are successfully demonstrated as TCEs in semi-transparent organic [11-13] and perovskite solar cells [14,15], which in many instances outperform the ITO-based counter parts.

In general, the optoelectronic properties of the metal mesh/network-based TCEs are strictly governed by their geometric and dimensional features such as, (i) metal mesh line width; (ii) pitch size or void area between the subsequent conducting mesh lines and (iii) thickness of the electrode layer [16]. With increasing metal mesh line width, electrical conductivity of the electrode increases and, concomitantly, transmittance decreases; whereas, the trend is reversed upon increasing the pitch size of the network structures. Similarly, increasing the metal electrode thickness reduces the overall sheet resistance, however, it also raises the surface roughness that creates additional shunt paths across the device stacks, impeding the device functionality. Further, the voids within the electrode mesh structure also cause an additional issue in solar cells as the charge carriers reaching these spaces are hardly collected by the electrodes. The lateral transport of charges across the void space towards the conducting mesh lines demands charge carrier diffusion length in tens of micrometer scale, which is not common in many solar cells. In such cases, the accumulated charges in the metal mesh void structures facilitate parasitic charge recombination events that reduce the overall photoconversion efficiency (PCE) of the solar cells $[13,16]$.

To overcome the surface roughness and lateral charge collection issues, the metal mesh structures are often employed in combination with thin conducting filler layers in devices as hybrid electrodes. The filler layer ensures lateral charge collection from the electrode void area to the electrode conducting line; however, this field-driven drift process is accompanied with significant ohmic losses, which is undesirable in any applications, particularly for solar cells. Along these lines, a variety of conducting filler materials such as PEDOT:PSS [15], zinc oxide [13], Al-doped zinc oxide [17] and $\mathrm{TiO}_{2}$ [18] have been tested in solar cells in combination with metal mesh electrodes, and a few such combinations have shown promising results.

As of now, the selection of a filler material for a metal mesh electrode is achieved based on the conventional figure of merit determined from the sheet resistance and optical transmission [4]. Based on this, a few studies regarding optimizing the charge collection using metal grids in organic solar cells and their modules are reported [19,20]. Interestingly, in these examples and also during the regular selection of the filler layers, the ohmic losses incurred by the hybrid metal mesh TCEs are not considered and the corresponding influencing parameters are not investigated to the best of our knowledge.

In this work, we use a simple numerical model to determine the optimal hybrid metal mesh geometry for maximizing the current collection in a perovskite solar cell and elucidate its dependency on filler sheet resistance and its effective charge carrier extraction distance, which is a function of the metal mesh electrode pitch size. To verify the theoretical predictions, we fabricated hybrid metal mesh electrodes with well-defined honeycombshaped metal network structures with varying pitch size and two different filler materials with different sheet resistance values, and applied them as TCE in perovskite solar cells. The solar cells parameters show a clear reliance of filler sheet resistance on the effective charge carrier extraction distance, which is in line with our numerical model. Based on these results, our model is expected to form the basis for selection rules for TCE, in addition to the existing figure of merit, to fabricate efficient metal mesh electrode/filler combinations, especially for lateral charge collection. 


\section{Materials and Methods}

\subsection{Preparation of Honeycomb Shaped Au and Cu-Network Electrodes on Glass Substrates}

Highly periodic, uniform Au-network structures with well-controlled geometric features were prepared on glass substrates using photolithographic technique. On precleaned, ozone treated glass substrates, photoresist LOR5B was spin cast at $5000 \mathrm{rpm}$ for $30 \mathrm{~s}$, followed by annealing at $180{ }^{\circ} \mathrm{C}$ for $7 \mathrm{~min}$. Furthermore, photoresist S1813 was spin cast using the same parameters and annealed at $120^{\circ} \mathrm{C}$ for $4 \mathrm{~min}$. With the appropriate prepatterned mask on top, the substrates were exposed to ultraviolet (UV) light for $3 \mathrm{~s}$ using a mask aligner. Furthermore, the substrates were treated with MF318 solution for $20 \mathrm{~s}$ followed by thorough washing in deionized water. The developed substrates were transferred to a physical vapor deposition (PVD) chamber, where $4 \mathrm{~nm}$ chromium and $70 \mathrm{~nm}$ gold were evaporated successively. After, the substrates were left in a beaker with $\mathrm{N}$-methylpyrrolidone (NMP) solvent overnight, and this was followed by ultrasonication for $4 \mathrm{~min}$ to remove all the photoresist. This results in well-defined honeycomb shaped Au-network electrodes on glass substrates. For $\mathrm{Cu}$-network electrodes, the same procedure was followed except approximately $70 \mathrm{~nm} \mathrm{Cu}$ was evaporated instead of $\mathrm{Au}$ in the PVD chamber.

\subsection{Deposition of Low Temperature $\mathrm{TiO}_{2}\left(\mathrm{LT}_{-} \mathrm{TiO}_{2}\right)$ and Aluminum-Doped Zinc Oxide (AZO) Filler Layers on Metal Network Electrodes}

Compact $\mathrm{TiO}_{2}$ layers of approximately $60 \mathrm{~nm}$ thickness were prepared on precleaned ITO (reference) and Au-network electrode substrates by spin casting a precursor solution containing $109 \mu \mathrm{L}$ of titanium tetrabutoxide, $3.4 \mu \mathrm{L}$ of $37 \% \mathrm{HCl}$ and $3 \mu \mathrm{L}$ of ethanol at $2000 \mathrm{rpm}$ for $50 \mathrm{~s}$, followed by annealing at $100{ }^{\circ} \mathrm{C}$ for $30 \mathrm{~min}$ in ambient conditions. The thickness of the $\mathrm{TiO}_{2}$ layers was adjusted to completely cover the metal network electrodes.

Approximately $70 \mathrm{~nm}$ thick aluminum-doped zinc oxide (AZO) layers were sputter deposited on ITO, Au-network and Cu-network electrode substrates in a Denton vacuum Explorer ${ }^{\circledR}$ system by employing confocal sputtering technique. A $2 \mathrm{wt} \% \mathrm{Al}$-doped ceramic target was used. The substrates were mounted on a stainless-steel holder, which was positioned $60 \mathrm{~mm}$ away from the target. The chamber was evacuated to a base pressure of $6 \times 10^{-6}$ bar prior to the sputtering process and during sputtering, the pressure was maintained at $6 \times 10^{-3}$ bar. The sputtering process was carried out with a radio-frequency (RF) power of $137 \mathrm{~W}$ for $9 \mathrm{~min}$, and the substrate holder was continuously rotated to ensure the film uniformity.

The thickness of the prepared $\mathrm{LT}-\mathrm{TiO}_{2}$ and AZO layers deposited on clean dummy glass slides was measured by using a profilometer. The same substrates were used to determine the sheet resistance of $\mathrm{LT}-\mathrm{TiO}_{2}$ and $\mathrm{AZO}$ layers by using four-point probe technique, and the values are $>1 \mathrm{G} \Omega / \square$ and $7000 \Omega / \square$, respectively. The $R_{s h}$ of the used ITO reference was determined as approximately $13 \Omega / \square$.

\subsection{Fabrication of Perovskite Solar Cells}

All the starting materials for solar cell preparation were purchased from SigmaAldrich (St. Louis, MO, USA) unless otherwise specifically stated, and used as received. The hole transporting material 2,2',7,7'-tetrakis-( $N, N$-di-p-methoxyphenylamine) 9,9'spirobifluorene (spiro-OMeTAD) was purchased from Merck KGaA, Darmstadt, Germany.

For $\mathrm{CH}_{3} \mathrm{NH}_{3} \mathrm{PbI}_{3}$ (MAPI) film deposition, $1 \mathrm{M} \mathrm{PbI}$ and methylammonium iodide were dissolved in dimethylformamide and stirred for at least $2 \mathrm{~h}$ at room temperature. To facilitate the substrate wetting properties of sputter prepared AZO layer, $60 \mu \mathrm{L}$ of phenyl-C61-butyricacid (PCBA $0.1 \mathrm{mg} / \mathrm{mL}$ ) in 1,2-dichlorobenzene solution was spin cast on AZO layer at $2000 \mathrm{rpm}$ for $50 \mathrm{~s}$. Once the MAPI precursor materials were completely dissolved, $80 \mu \mathrm{L}$ of this solution was spin cast on $\mathrm{LT}-\mathrm{TiO}_{2}$ and $\mathrm{AZO}$ substrates at $3000 \mathrm{rpm}$ for $50 \mathrm{~s}$. While the substrates started spinning, right after $8 \mathrm{~s}, 200 \mu \mathrm{L}$ of toluene (orthogonal solvent) was continuously dripped onto the substrates. Furthermore, the substrates were annealed at $100{ }^{\circ} \mathrm{C}$ for $25 \mathrm{~min}$ on a hot plate inside a $\mathrm{N}_{2}$ filled glovebox, resulting in 
an approximately $400 \mathrm{~nm}$ thick uniform MAPI layer. Successively, a hole transporting layer was deposited onto the perovskite layer by spin casting a chlorobenzene solution of spiro-OMeTAD (72.3 mg/mL), $43.2 \mu \mathrm{L}$ of 4-tert-butyl-pyridine (TBP), and $26.3 \mu \mathrm{L}$ of LiTFSI (520 mg/mL in acetonitrile) at $2000 \mathrm{rpm}$ for $50 \mathrm{~s}$ in the glovebox. These substrates were stored overnight in a dry box (relative humidity $<10 \%$ ) to facilitate the air doping of spiro-OMeTAD layer. Finally, approximately $70 \mathrm{~nm}$ thick gold back contact was deposited in a PVD chamber, completing the solar cells. The active area of the fabricated devices is either 0.09 or $0.16 \mathrm{~cm}^{2}$ defined by the cross-section area of the bottom and top electrodes.

Characterization of the solar cells was carried out by using an Oriel solar simulator under AM 1.5, $1000 \mathrm{~W} \mathrm{~m}^{-2}$ conditions and a Keithley 2400 source meter. The currentvoltage $(\mathrm{I}-\mathrm{V})$ curves were measured from $+1.5 \mathrm{~V}$ to $0.5 \mathrm{~V}$ and back at the scan rate of approximately $130 \mathrm{mV} \mathrm{s}^{-1}$ under $\mathrm{N}_{2}$ atmosphere. The photovoltaic parameters such as $J_{s c}$, $V_{o c}$, fill factor (FF) and PCE were determined from the corresponding I-V curves using a home-built software.

\section{Results}

One of the major advantages of metal mesh electrodes is their excellent transparency $(>85 \%)$, which is a result of their geometry of thin conducting mesh lines with void spaces in between. With increasing distance between the successive metal mesh lines (pitch size), the transparency of the electrode structure improves linearly, making it appealing for transparent and semi-transparent optoelectronic applications. However, in devices that demand charge collection or injection into the void area such as solar cells or organic light emitting diodes (OLEDs), a trade-off between the transparency and conductivity is achieved by controlling the pitch size, and an addition of a conducting filler layer ensures the maximum lateral charge collection or injection, naturally, at the expense of voltage. The impact of such current and voltage losses on organic solar cells performance is addressed in a few reports. For example, Galagan et al. addressed the influence of electrode pitch size in hexagonally structured Ag nanowire grids [19], whereas Jacobs et al. studied different possibilities for incorporating metal wires for improved charge collection in thin film solar cells [21]. Cravino et al., studied the current contribution from neighboring regions around the active area of an organic solar cell by considering the distances between the electrodes and sheet resistance of the charge collecting layer such as PEDOT:PSS used in these devices [22]. The consequences of designing charge collecting metal grids and associated voltage or current loss in modules have also been addressed [20,23]. In spite of these studies, a more realistic picture on ohmic losses in solar cells employing the hybrid metal mesh electrodes can be obtained by combining the sheet resistance $\left(R_{s h}\right)$ of the filler layer, overall charge carrier density in the device and the distance over which the charge carriers needs to be transported $(l)$ from the void area to the conducting metal mesh line. To address the voltage and current losses originating from the hybrid metal mesh TCE, we adopted a numerical expression similar to Cravino et al. [22], which they used to estimate additional charge collection from neighboring regions in organic solar cells, and the expression is,

$$
\Delta V=\int \frac{R_{s h} \cdot J_{s c} \cdot l \cdot w_{e l}}{w_{\text {filler }}} d l
$$

where $\Delta V$ is voltage loss, $R_{s h}$ is sheet resistance of the filler layer, $J_{s c}$ is photocurrent density, $l$ is the distance over which the charge carrier needs to be transported through the filler layer (charge extraction length $\approx$ about half of the pitch size), $w_{e l}$ is the width of the metal mesh line and $w_{\text {filler }}$ is the effective width of the filler layer depending on the geometry as well as $w_{e l}$ value.

The solution for this expression can be derived using a model system. Consider a perovskite solar cell employed with a honeycomb metal mesh hybrid electrode showing the maximum $J_{s c}$ of $20 \mathrm{~mA} / \mathrm{cm}^{2}$. Here, the value of $w_{\text {filler }}$ is assumed to be $20 w_{e l}$, since the pitch size is approx. 20 times the $w_{e l}$ value. Solving Equation (1) for the process of transporting a charge carrier located in the void at " $l$ " distance from the conducting mesh 
lines (as depicted in Figure 1 inset) results in the plot of $l$ vs. $R_{s h}$ as shown in Figure 1 for the voltage loss of maximum $100 \mathrm{mV}$ and minimum $10 \mathrm{mV}$.

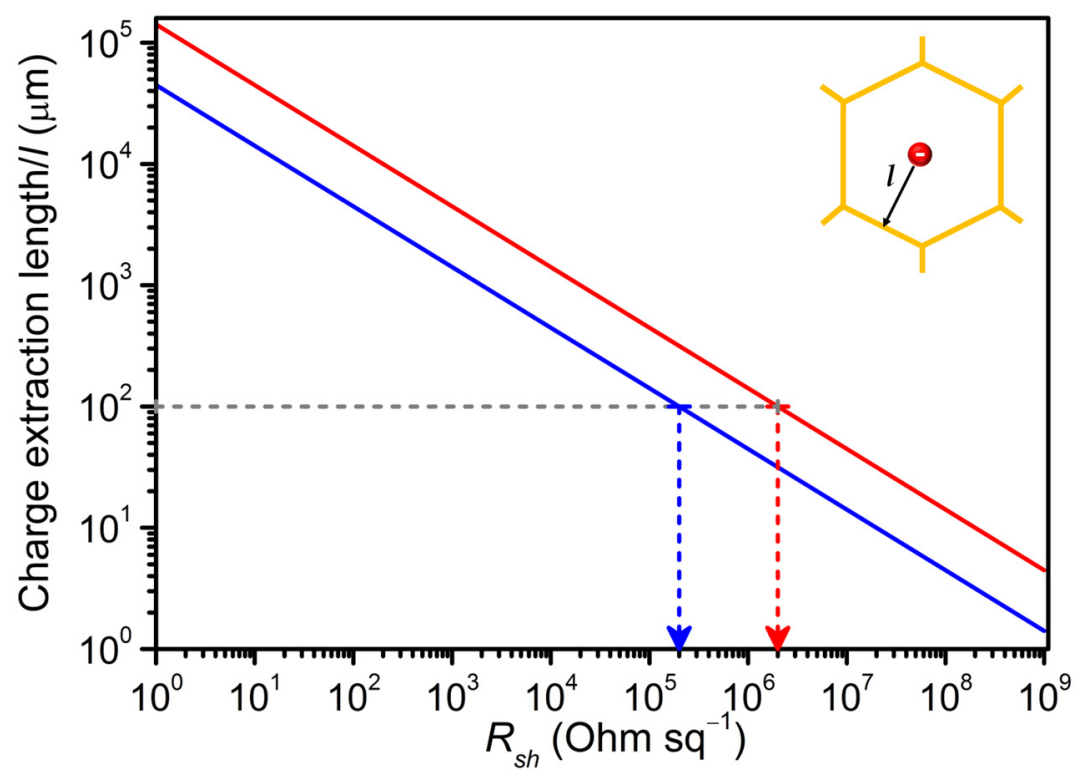

Figure 1. Relation between the sheet resistance $\left(R_{s h}\right)$ of the filler layer and charge carrier extraction length $(l)$ from a void space in the metal network electrode as shown in the inset scheme. The plots are derived by assuming $J_{s c}$ of $20 \mathrm{~mA} / \mathrm{cm}^{2}$ and $\Delta V$ of $100 \mathrm{mV}$ (red) or $10 \mathrm{mV}$ (blue) in a perovskite solar cell. The horizontal grey line intercepting red and blue lines notifies the required $R_{s h}$ value of the filler to collect the charges from $100 \mu \mathrm{m}$ distance with the voltage loss of 100 and $10 \mathrm{mV}$, respectively.

The plot clearly shows the limitations of the possible combinations of $l$ and $R_{s h}$ for the anticipated voltage loss. For example, to extract a charge carrier from a distance of $100 \mu \mathrm{m}$ at the expense of $10 \mathrm{mV}$, the filler should have the maximum $R_{s h}$ of $1 \times 10^{5} \Omega / \square$ (blue dotted arrow). However, in the same device for the same $l$ value, if one can afford a 10-fold higher voltage loss $(100 \mathrm{mV})$ then the filler with the maximum $R_{s h}$ of $1 \times 10^{6}$ $\Omega / \square$ (red dotted line) can be used to extract the charges. It is also clear from Figure 1 that for the same filler layer (same $R_{s h}$ ), with increasing $l$, i.e., upon increasing the pitch size of the metal mesh nanostructures, the loss in voltage also increases. In other words, for each threefold increase in distance between the charge carrier and the conducting mesh line, a minimum of 10 -fold higher voltage is required to extract this carrier to contribute to the device photocurrent. This is a significant loss for any high-performing optoelectronic devices, in particular, for perovskite solar cells.

On the other hand, reducing Equation (1) to obtain the relation between $R_{s h}$ vs. $l$ for the above mentioned model system results in:

$$
\frac{1}{R_{s h}}=l^{2} \frac{J_{s c}}{20 \Delta V}
$$

which clearly evidences an inverse quadratic relationship between the filler $R_{s h}$ and $l$ value. This means, with an order of increase in $l$ value, i.e., for a metal mesh structure with an order of increased pitch size requires a filler layer with at least two orders of magnitude reduced $R_{s h}$ to collect a charge carrier with a same voltage loss value. In absolute terms, for the given conditions, a filler with a sheet resistance of $100 \Omega / \square$ can effectively transport a charge carrier from a distance of approximately $4 \mathrm{~mm}$ with $10 \mathrm{mV}$ loss in the voltage. If $l$ exceeds beyond $4 \mathrm{~mm}$, to extract the charge carriers from a metal network void without losing further voltage, it is essential to use a filler with further reduced $R_{s h}$. These findings are of paramount importance for solar cells as they assist in mitigating the additional parasitic ohmic losses by suggesting the maximum limit of $R_{s h}$ of the filler layer for a metal 
mesh structure with a specific pitch size. Interestingly, the plot also helps to predict the performance loss in any optoelectronic device based on the metal mesh electrode geometry and filler layer combination, prior to device fabrication.

To verify these theoretical findings, we prepared honeycomb-shaped Au-network electrodes on glass substrates with increasing pitch size and $w_{e l}$ using the photolithographic technique, in combination with two different filler layers showing significantly different $R_{s h}$ values. Figure 2a-c show the lateral scanning electron microscopic (SEM) images of the prepared Au-network electrode structures along with their corresponding $w_{e l}$ and pitch size. The maximum $l$ value for the corresponding void spaces is equivalent to the distance between the center of the honeycomb structure and the middle of a metal mesh line, which can be obtained by determining the radius $(r=a \times \sqrt{ } 3 / 2)$ of inscribed circles in the hexagons, where "a" is the length of a side of the hexagon. The calculated $l$ values corresponding to the honeycomb network pitch size are also listed in Figure $2 \mathrm{a}-\mathrm{c}$.

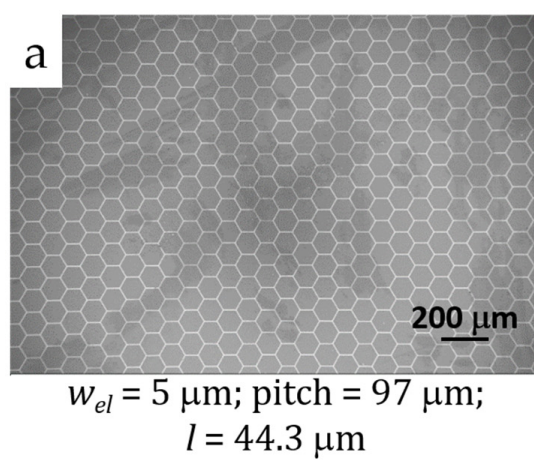

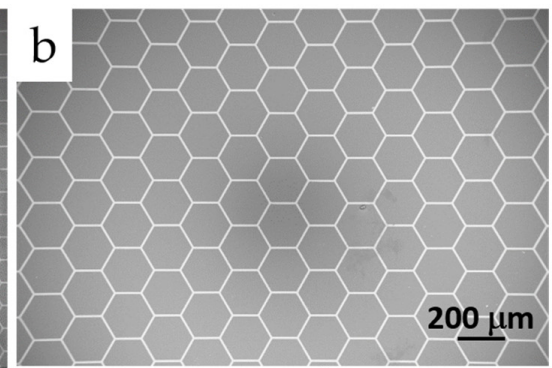

$w_{e l}=10 \mu \mathrm{m} ;$ pitch $=196 \mu \mathrm{m}$; $l=90.6 \mu \mathrm{m}$

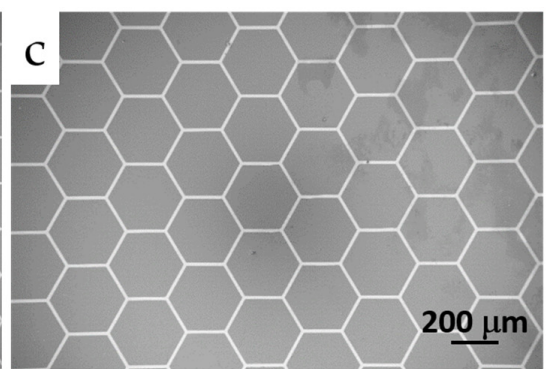

$w_{e l}=15 \mu \mathrm{m} ;$ pitch $=293 \mu \mathrm{m}$; $l=141 \mu \mathrm{m}$
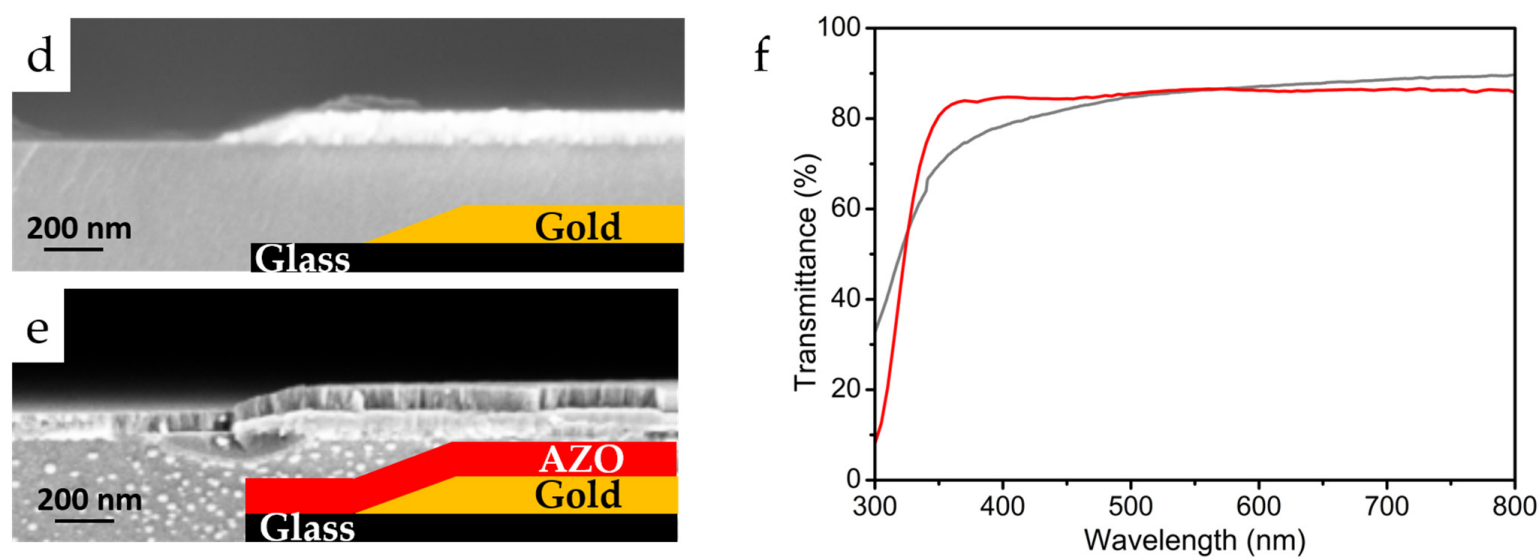

Figure 2. Scanning electron microscopy (SEM) images of Au-network electrodes with the pitch size of (a) $97 \mu \mathrm{m},(\mathbf{b}) 196$ $\mu \mathrm{m}$ and (c) $293 \mu \mathrm{m}$ deposited on glass substrates showing uniform honeycomb structures with well-defined geometry and dimensions over a large range; cross-sectional SEM images of (d) Au-network structure on a glass and (e) conformal covering of Au-network structure on glass by sputter-deposited aluminum-doped zinc oxide (AZO) layer and corresponding schemes as inset; (f) transmittance spectra of $\mathrm{LT}^{-\mathrm{TiO}_{2}}$ (grey) and $\mathrm{AZO}$ (red)conducting filler layers deposited Au-network (pitch $=97 \mu \mathrm{m}$ ) electrodes on glass substrates.

It is evident from the images that the prepared honeycomb Au-network structures are uniform and highly periodic with well-controlled geometry and dimensions, as a result of the photolithographic technique. Notably, the geometry fill factor of these metal mesh electrodes was maintained as $10 \%$ despite increasing the pitch size, by adjusting the $w_{e l}$ accordingly $(5,10$ and $15 \mu \mathrm{m})$. This ensures the same sheet resistance value for all the metal mesh structures irrespective of the pitch size. The influence of increasing $l$ value as a consequence of network pitch size and $R_{s h}$ of the filler layers on ohmic losses is evaluated by employing these metal nanostructures as hybrid TCEs in planar perovskite solar cells. 
Using these nanostructured electrodes, two sets of planar perovskite solar cells were prepared by employing low temperature $\mathrm{TiO}_{2}\left(\mathrm{LT}_{-}-\mathrm{TiO}_{2}, R_{s h}>1 \mathrm{G} \Omega / \square\right)$ and Al-doped $\mathrm{ZnO}\left(\mathrm{AZO}, R_{s h}=7000 \Omega / \square\right)$ as electron transport as well as conducting filler layers. An approximately $60 \mathrm{~nm}$ thick $\mathrm{LT}^{-} \mathrm{TiO}_{2}$ layer was deposited on Au-network electrode on glass substrates by using sol-gel method, which is known to cover the electrode structure uniformly [13]. On the other hand, approximately $70 \mathrm{~nm}$ thick AZO layer was prepared on Au-networks via the RF sputtering technique. The conformal coverage of Au-networks by AZO layer is clearly evidenced by the comparative cross-sectional SEM images of a glass substrate containing the Au-network structure before and after AZO deposition as shown in Figure 2d,e.

The selection of $\mathrm{LT}-\mathrm{TiO}_{2}$ and $\mathrm{AZO}$ for this investigation was based on the similarity in their work function $(\approx 4 \mathrm{eV})[24,25]$, which circumvents possible differences in contact resistance at the Au-network electrode/electron transport layer interface. Also, as shown in Figure $2 \mathrm{f}$, the transmittance of both $\mathrm{LT}-\mathrm{TiO}_{2}$ and $\mathrm{AZO}$ deposited Au network structures is quite comparable $(80 \%)$ in the visible region, which safely neglects the possible light transmission differences as a reason for corresponding solar cells performance differences. This transmittance value is less than that of the conventional ITO TCE (85\%) in the visible region [13]. Further, the stark contrast in their measured sheet resistance values can lead to unambiguous conclusions regarding the correlation of $R_{s h}$ and $l$ of hybrid TCEs. For this reason, both the electrodes and filler layers are designed and prepared in a careful way that the possible differences in the solar cells performance can be attributed solely to the change in the $l$ value and $R_{s h}$ of the conducting filler layers.

Furthermore, planar perovskite solar cells are fabricated on these conducting filler layers by successively depositing photoactive MAPI, hole transporting spiro-OMeTAD layer and gold top electrode (see Materials and Methods). The final device geometry is Au-network electrode/LT-TiO 2 or AZO/MAPI/Spiro-OMeTAD/Au and is schematically shown in Figure 3a. In addition to the Au-network electrode-based solar cells, individual reference devices were also fabricated with ITO electrodes for $\mathrm{LT}^{-\mathrm{TiO}_{2}}$ and $\mathrm{AZO}$ filler layers under similar experimental conditions.

a)

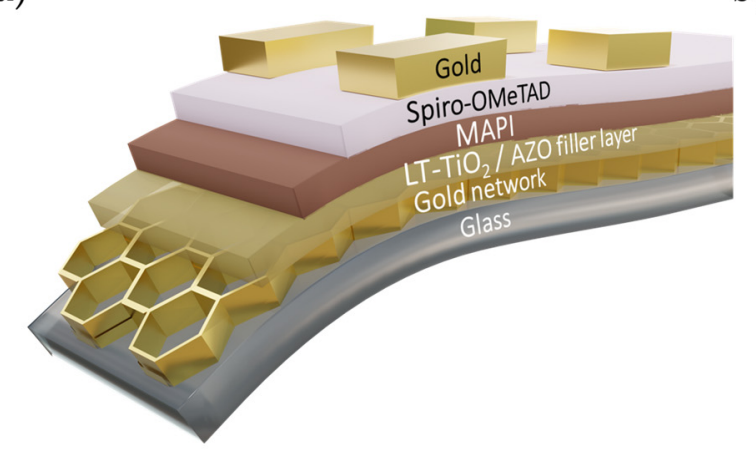

b)

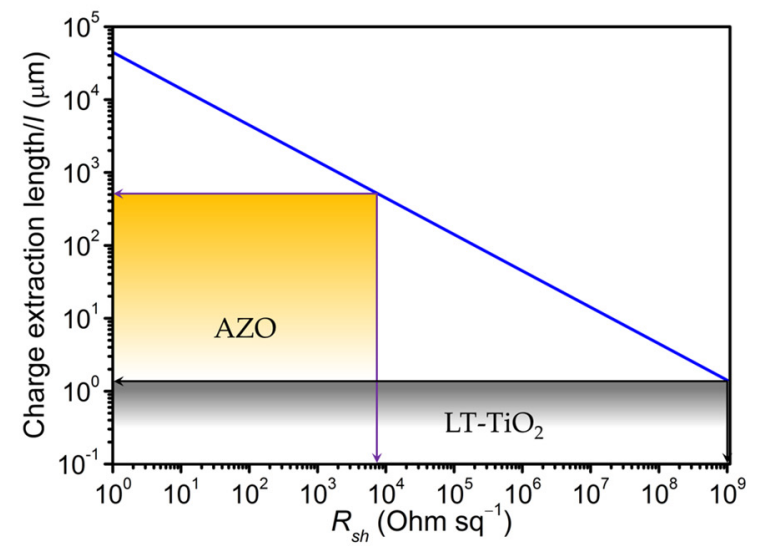

Figure 3. (a) Schematic representation of the planar perovskite solar cell device configuration and corresponding stacks used in this work; (b) Effective charge extraction length of $\mathrm{LT}_{-} \mathrm{TiO}_{2}$ and $\mathrm{AZO}$ filler layers corresponding to their $R_{s h}$ values deduced for $10 \mathrm{mV}$ voltage loss from Figure 1.

Prior characterizing the solar cells, the maximum possible $l$ values, i.e., effective charge extraction length at the voltage loss of $10 \mathrm{mV}$ for both $\mathrm{LT}-\mathrm{TiO}_{2}$ and $\mathrm{AZO}$ are deduced from Figure 1 based on their $R_{s h}$ values, and are schematically shown in Figure $3 \mathrm{~b}$. The plot indicates that the RF sputtered $\mathrm{AZO}\left(R_{s h} \approx 7000 \Omega / \square\right)$ can theoretically transport a charge carrier up to approximately $400 \mu \mathrm{m}$ distance at the expense of $10 \mathrm{mV}$; whereas, due to very high $R_{s h}$ value ( $>1 \mathrm{G} \Omega / \square$ ) of the prepared $\mathrm{LT}-\mathrm{TiO}_{2}$, the corresponding maximum lateral charge transport distance is determined to be approximately $1 \mu \mathrm{m}$ for the same voltage. The substantial difference in their effective charge extraction distance is expected 
to play a vital role in dictating the corresponding solar cell performance. Based on the solar cells results obtained using Au-network/AZO electrode, we also tested the viability of preparing a similar mesh using less expensive $\mathrm{Cu}$ instead of $\mathrm{Au}$, applied it in combination with AZO and compared with the devices employing Au-network/AZO hybrid electrode.

The solar cells were mechanically sealed in test chambers under nitrogen atmosphere and characterized for their photovoltaic features. The measured current-voltage (I-V) curves for solar cells prepared on Au-network electrodes with varying pitch size in combination with $\mathrm{LT}-\mathrm{TiO}_{2}$ and $\mathrm{AZO}$ filler layers and corresponding ITO reference devices are exhibited in Figure 4. The determined parameters from the respective I-V measurements are collected in Table 1.
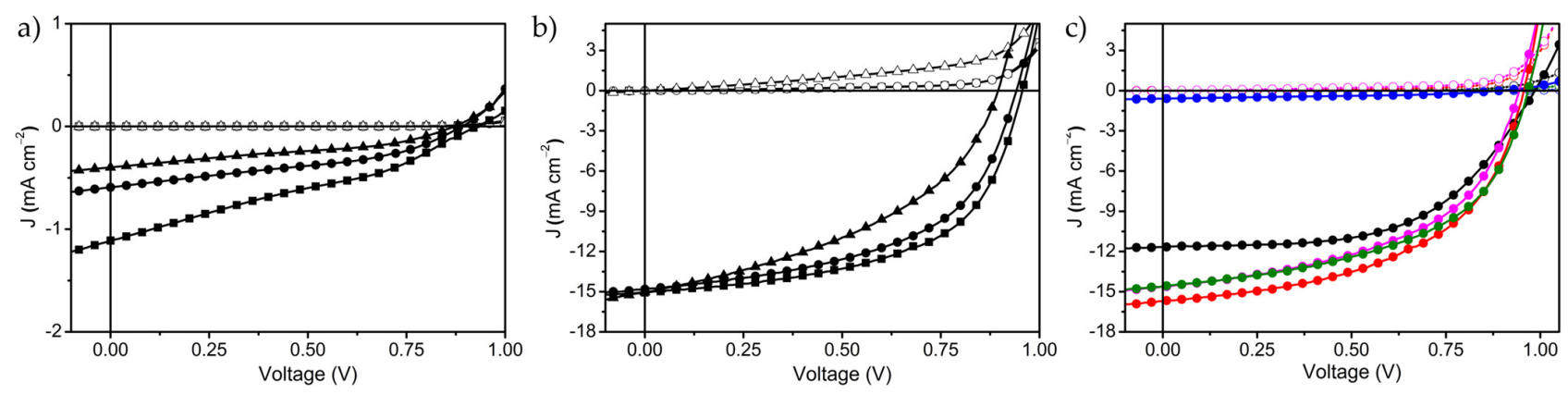

Figure 4. Dark (open symbol-lines) and light (filled symbol-lines) I-V curves of planar perovskite solar cells prepared on Aunetwork electrodes with the pitch size of $97 \mu \mathrm{m}$ (square-line), $196 \mu \mathrm{m}$ (circle-line) and $293 \mu \mathrm{m}$ (triangle-line) containing (a) $\mathrm{LT}^{-\mathrm{TiO}_{2}}$ and (b) AZO filler layers; (c) comparison of dark (open symbol-lines) and light (filled symbol-lines) current-voltage (I-V) curves of perovskite solar cells prepared on reference ITO/LT-TiO 2 (black-circle-line), ITO/AZO (red-circle-line) and hybrid Au-network/LT-TiO 2 (blue-circle-line), Au-network/AZO (magenta-circle-line) and Cu-network/AZO (green-circleline) electrodes with $196 \mu \mathrm{m}$ pitch size.

Table 1. Photovoltaic parameters of the planar perovskite solar cells prepared on Au-network with increasing charge carrier extraction length, and $\mathrm{LT}_{-} \mathrm{TiO}_{2}$ and $\mathrm{AZO}$ conducting filler layers.

\begin{tabular}{|c|c|c|c|c|c|c|c|c|}
\hline $\begin{array}{l}\text { Electrode and } \\
\text { Filler Layer }\end{array}$ & $\begin{array}{l}\text { Pitch Size } \\
\qquad(\mu \mathrm{m})\end{array}$ & $l(\mu \mathrm{m})$ & $\begin{array}{c}\mathrm{J}_{\mathrm{sc}} \\
\left(\mathrm{mA} / \mathrm{cm}^{2}\right)\end{array}$ & $\mathrm{V}_{\mathrm{oc}}(\mathrm{V})$ & FF (\%) & PCE (\%) & $\begin{array}{c}R_{S} \\
\left(\Omega \cdot \mathrm{cm}^{2}\right)\end{array}$ & $\begin{array}{c}R_{\text {shunt }} \\
\left(\Omega \cdot \mathrm{cm}^{2}\right)\end{array}$ \\
\hline $\begin{array}{c}\text { ITO/LT-TiO } 2 \\
\text { (Reference) }\end{array}$ & - & - & 11.7 & 0.99 & 56 & 6.5 & 1380 & 1028 \\
\hline \multirow{3}{*}{$\begin{array}{c}\text { Au network/ } \\
\text { LT-TiO }_{2}\end{array}$} & 97 & 44.3 & 1.11 & 0.93 & 31 & 0.32 & 1562 & 938 \\
\hline & 196 & 90.6 & 0.59 & 0.89 & 39 & 0.21 & 2500 & 2215 \\
\hline & 293 & 141 & 0.40 & 0.87 & 37 & 0.13 & 4545 & 2839 \\
\hline $\begin{array}{l}\text { ITO/AZO } \\
\text { (Reference) }\end{array}$ & - & - & 15.7 & 0.96 & 52 & 7.9 & 448 & 395 \\
\hline \multirow{3}{*}{$\begin{array}{c}\text { Au network/ } \\
\text { AZO }\end{array}$} & 97 & 44.3 & 15.1 & 0.96 & 56 & 8.2 & 136 & 473 \\
\hline & 196 & 90.6 & 14.8 & 0.94 & 53 & 7.4 & 117 & 377 \\
\hline & 293 & 141 & 15 & 0.90 & 43 & 5.8 & 42 & 183 \\
\hline $\begin{array}{c}\text { Cu network/ } \\
\text { AZO }\end{array}$ & 196 & 90.6 & 14.6 & 0.97 & 52 & 7.4 & 151 & 371 \\
\hline
\end{tabular}

It should be noted that the prepared perovskite device stacks are not optimized for the maximum PCE. Nevertheless, they are employed in these studies as testbeds due to the excellent photovoltaic properties of MAPI, known for high and similar photocarrier density in all the prepared devices, which is one of the essential criteria to derive the relationship shown in Figures 1 and 3. On the other hand, the ease of preparation and high reproducibility of the corresponding photovoltaic parameters of the planar perovskite solar cells enable investigating the impact of intrinsic changes in one of the device stacks on device performance [26]. Therefore, the main discussion is restricted to the relative 
differences in the photovoltaic parameters of the devices with increasing Au-network pitch size and different filler layers.

\section{Discussion}

Figure $4 \mathrm{a}, \mathrm{b}$ display the measured I-V curves of the perovskite solar cells prepared on Au-network hybrid TCEs with $\mathrm{LT}-\mathrm{TiO}_{2}$ and AZO filler layers, respectively. Considering the Au-network/LT- $\mathrm{TiO}_{2}$ based perovskite solar cells, they exhibit photovoltaic character, however, the determined $J_{s c}, V_{\mathrm{OC}}$ and fill factor (FF) values are remarkably poor, irrespective of the Au-network pitch size (Table 1). On the other hand, with increasing Au-network pitch size from 97 to $293 \mu \mathrm{m}$, the $R_{s}$ value of the respective perovskite solar cells linearly increases from 1500 to $4500 \Omega \cdot \mathrm{cm}^{2}$ and $R_{\text {shunt }}$ also increases relatively. This emphasizes the influence of Au-network pitch size on device performance upon employed with a poorly conducting filler layer such as $\mathrm{LT}-\mathrm{TiO}_{2}$. The reference solar cells (Figure 4c) prepared with LT- $\mathrm{TiO}_{2}$ on ITO electrode (ITO/LT-TiO ${ }_{2}$ ) also show $R_{s}$ and $R_{\text {shunt }}$ values comparable to a device with the Au-network/LT- $\mathrm{TiO}_{2}$ TCE (97 $\mu \mathrm{m}$ pitch size, Table 1), however, it displays $J_{s c}$ of $11.7 \mathrm{~mA} / \mathrm{cm}^{2}, V_{o c}$ of $0.99 \mathrm{~V}$ and FF of $56 \%$ resulting in an overall PCE of $6.5 \%$, which is comparable with the solar cells containing $\mathrm{LT}-\mathrm{TiO}_{2}$ prepared using a similar method [27]. This clearly suggests that the device stacks in Au-network/LT-TiO 2 TCE-based solar cells are not limiting the performance. On the other hand, the calculated maximum allowable $l$ value for $\mathrm{LT}_{-} \mathrm{TiO}_{2}$ (approximately $1 \mu \mathrm{m}$ ) based on its $R_{s h}$ is exceeded well in all the prepared Au-network electrode structures under investigation. This is anticipated to result in poor lateral charge extraction by LT- $\mathrm{TiO}_{2}$ towards the metal mesh lines, and consequently leads to charge carriers' accumulation and recombination at the electrode/ $/ \mathrm{LT}-\mathrm{TiO}_{2}$ interface and poor $J_{s c}, V_{o c}$ and PCE values. Furthermore, upon comparing the photovoltaic parameters of the devices within the same series, both $J_{s c}$ and $V_{o c}$ considerably increase with decreasing $l$ value from 141 to $44.3 \mu \mathrm{m}$ in the hybrid TCEs resulting in 2-3 fold higher PCE values. These experimental observations are in line with the predictions based on our numerical model.

In the case of Au-network/AZO-based hybrid electrodes, the calculated effective charge carrier transport distance $(400 \mu \mathrm{m})$ of the filler layer is well above the $l$ values corresponding to the Au-network structures used. Thus, theoretically, AZO is expected to effectively extract all the photogenerated charge carriers from the Au-network electrode void space without significant ohmic losses. In fact, all the perovskite solar cells prepared on Au-network/AZO hybrid TCEs display comparable photovoltaic parameters including $R_{S}$ and $R_{\text {shunt }}$ values with those of the ITO/AZO based reference device (Figure $4 \mathrm{~b}, \mathrm{c}$, and Table 1). With increasing $l$ from $44.3 \mu \mathrm{m}$ (pitch $=97 \mu \mathrm{m})$ up to $141 \mu \mathrm{m}$ (pitch $=293 \mu \mathrm{m})$ in Au-network/AZO-based devices, $J_{s c}$ is maintained at approximately $15 \mathrm{~mA} / \mathrm{cm}^{2}$ with a slight fluctuation in $V_{o c}$. Interestingly, unlike the devices prepared on Au-network/LT-TiO TCEs, the $R_{S}$ and $R_{\text {shunt }}$ values of the respective solar cells remain comparable irrespective of the Au-network pitch size (Table 1), suggesting the influence of the conducting filler layer. The fact that there is no current collection loss up to a pitch size of $293 \mu \mathrm{m}$ is in full agreement with our model, which allows the charge extraction of up to $400 \mu \mathrm{m}$ for a $10 \mathrm{mV}$ drop. We still observe a slight decrease in $V_{o c}$ and $\mathrm{FF}$ as the pitch size is increased to $293 \mu \mathrm{m}$, which could be due to: (i) shunt loss originating from device stack preparation steps, and/or (ii) the effective charge carrier extraction distance of AZO is overestimated as the plots in Figure 1 are derived by using the upper limit of $J_{s c}, w_{e l}$ and $w_{\text {filler }}$ values, and/or (iii) occurrence of charge carrier recombination events at the perovskite/electron transport layer interface, which generally reduces the $V_{o c}$ and FF [28].

Using this same strategy, we tested if Earth-abundant and less expensive copper grids in combination with AZO can be used as a hybrid TCE in perovskite solar cells. Figure $4 \mathrm{c}$ showing the measured I-V curves of perovskite solar cells containing ITO/LT$\mathrm{TiO}_{2}$ and ITO/AZO reference electrodes, and Au-network/LT-TiO ${ }_{2}$, Au-network/AZO and Cu-network/AZO hybrid TCEs with the pitch size of $196 \mu \mathrm{m}$ and the determined corresponding photovoltaic parameters listed in Table 1 indicate similar photovoltaic 
behavior of hybrid Cu-network/AZO based solar cells without any loss in the current collection. This first result is promising and opens the possibility of exploiting the combination of copper grid electrodes and a variety of appropriate filler layers as hybrid TCEs for semi-transparent perovskite solar cell applications.

\section{Conclusions}

In this work, we emphasized that charge carrier extraction process from the voids of metal mesh electrode using conducting filler layer depends heavily on the sheet resistance of the latter and metal electrode pitch size. The consequent losses in current and voltage can be considered as ohmic losses, which could be detrimental to optoelectronic device performance, if the sheet resistance of the filler layer is very high. To calculate the extent of such losses, a simple numerical expression involving the distance over which the carrier needs to be transported $(l)$, sheet resistance of the filler layer $\left(R_{s h}\right)$ and charge carrier density of the device is proposed. By solving this expression, the interplay between $R_{s h}$ and $l$ of the filler layer for conditions relevant for solar cells applications is derived. The corresponding plots suggest the following: (i) with increasing $l$ value, voltage loss also increases for the same filler layer; (ii) with increasing $R_{s h}$ of the filler layer, the effective $l$ decreases quadratically for an assumed voltage loss value. These results are experimentally verified by fabricating two sets of TCEs based on Au-network electrodes with varying pitch size and with $\mathrm{LT}_{-\mathrm{TiO}}$ and $\mathrm{AZO}$ filler layers, and testing them in perovskite solar cells. Evidently, Au-network/LT-TiO ${ }_{2}$-based TCE exhibited extremely poor charge extraction behavior compared to the respective reference device, and displayed a clear trend between increasing $l$ values and $J_{s c}$ and $V_{o c}$ parameters, which are in excellent agreement with the predicted model. On the other hand, using an improved conductor as filler layer, an extremely good charge collection behavior was observed in devices using Au-network/AZO as well as $\mathrm{Cu}$ network/AZO based TCEs. These observations highlight the correlation and impact of $R_{s h}$ of the filler layer on lateral charge extraction efficiency towards the metal mesh electrodes, and validate the predictions from our numerical model. These experimental results suggest that the proposed model can help in determining the ohmic losses in optoelectronic devices originating from the hybrid metal mesh TCEs prior to device preparation. In addition, the derived relation between the effective charge carrier extraction distance and the filler layer sheet resistance could enable selecting the appropriate conducting filler layers for specific metal mesh electrode geometry and dimensions aimed for a variety of transparent and semi-transparent optoelectronic applications.

Author Contributions: Conceptualization, M.T. and C.R.S.; methodology, C.R.S.; validation, T.P.G., C.D.H. and J.M.; formal analysis, C.R.S., J.M., T.P.G. and C.D.H.; writing-original draft preparation, J.M.; writing — review and editing, J.M. and M.T.; supervision, M.T.; project administration, M.T.; funding acquisition, M.T. All authors have read and agreed to the published version of the manuscript.

Funding: This research was funded by Bavarian ministry of Science and Arts, Solar technologies Go Hybrid, (Soltech), Deutsche Forschungsgemeinschaft under SFB 840 and Bundesministerium für Bildung und Forschung (METNETWORK).

Data Availability Statement: The data presented in this study are available on request from the corresponding author.

Acknowledgments: We acknowledge Christoph Hunger, Papierfabrik Louisenthal and Giridhar Kulkarni, CENS, Bangalore for fruitful discussions on this topic. Jonas Mayer is acknowledged for his contribution in preparing AZO layers used in this study.

Conflicts of Interest: The authors declare no conflict of interest. 


\section{References}

1. Internet of Things (Iot) and Non-Iot Active Device Connections Worldwide from 2010 to 2025. Available online: https:/ /www. statista.com/statistics/1101442/iot-number-of-connected-devices-worldwide/ (accessed on 1 May 2021).

2. Global Energy Review 2020. Available online: https://www.iea.org/reports/global-energy-review-2020 (accessed on 1 May 2021).

3. Statistical Review of World Energy. Available online: https://www.bp.com/en/global/corporate/energy-economics/statisticalreview-of-world-energy.html (accessed on 1 May 2021).

4. Hecht, D.S.; Hu, L.; Irvin, G. Emerging Transparent Electrodes Based on Thin Films of Carbon Nanotubes, Graphene, and Metallic Nanostructures. Adv. Mater. 2011, 23, 1482-1513. [CrossRef] [PubMed]

5. Kim, N.; Kee, S.; Lee, S.H.; Lee, B.H.; Kahng, Y.H.; Jo, Y.-R.; Kim, B.-J.; Lee, K. Highly Conductive PEDOT:PSS Nanofibrils Induced by Solution-Processed Crystallization. Adv. Mater. 2014, 26, 2268-2272. [CrossRef] [PubMed]

6. Kaltenbrunner, M.; Adam, G.; Głowacki, E.D.; Drack, M.; Schwödiauer, R.; Leonat, L.; Apaydin, D.H.; Groiss, H.; Scharber, M.C.; White, M.S.; et al. Flexible High Power-Per-Weight Perovskite Solar Cells with Chromium Oxide-Metal Contacts for Improved Stability in Air. Nat. Mater. 2015, 14, 1032-1039. [CrossRef] [PubMed]

7. Yoon, J.; Sung, H.; Lee, G.; Cho, W.; Ahn, N.; Jung, H.S.; Choi, M. Superflexible, High-Efficiency Perovskite Solar Cells Utilizing Graphene Electrodes: Towards Future Foldable Power Sources. Energy Environ. Sci. 2017, 10, 337-345. [CrossRef]

8. Li, R.; Xiang, X.; Tong, X.; Zou, J.; Li, Q. Wearable Double-Twisted Fibrous Perovskite Solar Cell. Adv. Mater. 2015, 27, 3831-3835. [CrossRef] [PubMed]

9. Liu, L.; Cao, K.; Chen, S.; Huang, W. Toward See-through Optoelectronics: Transparent Light-Emitting Diodes and Solar Cells Adv. Opt. Mater. 2020, 8, 2001122. [CrossRef]

10. Azani, M.-R.; Hassanpour, A.; Torres, T. Benefits, Problems, and Solutions of Silver Nanowire Transparent Conductive Electrodes in Indium Tin Oxide (Ito)-Free Flexible Solar Cells. Adv. Energy Mater. 2020, 10, 2002536. [CrossRef]

11. Kang, M.-G.; Xu, T.; Park, H.J.; Luo, X.; Guo, L.J. Efficiency Enhancement of Organic Solar Cells Using Transparent Plasmonic Ag Nanowire Electrodes. Adv. Mater. 2010, 22, 4378-4383. [CrossRef]

12. Hunger, C.; Rao, K.D.M.; Gupta, R.; Singh, C.R.; Kulkarni, G.U.; Thelakkat, M. Transparent Metal Network with Low Haze and High Figure of Merit Applied to Front and Back Electrodes in Semitransparent ITO-Free Polymer Solar Cells. Energy Technol. 2015, 3, 638-645. [CrossRef]

13. Rao, K.D.M.; Hunger, C.; Gupta, R.; Kulkarni, G.U.; Thelakkat, M. A Cracked Polymer Templated Metal Network as a Transparent Conducting Electrode for ITO-Free Organic Solar Cells. Phys. Chem. Chem. Phys. 2014, 16, 15107-15110. [CrossRef]

14. Lu, H.; Sun, J.; Zhang, H.; Lu, S.; Choy, W.C.H. Room-Temperature Solution-Processed and Metal Oxide-Free Nano-Composite for the Flexible Transparent Bottom Electrode of Perovskite Solar Cells. Nanoscale 2016, 8, 5946-5953. [CrossRef]

15. Li, Y.; Meng, L.; Yang, Y.; Xu, G.; Hong, Z.; Chen, Q.; You, J.; Li, G.; Yang, Y.; Li, Y. High-Efficiency Robust Perovskite Solar Cells on Ultrathin Flexible Substrates. Nat. Commun. 2016, 7, 10214. [CrossRef]

16. Lee, H.B.; Jin, W.-Y.; Ovhal, M.M.; Kumar, N.; Kang, J.-W. Flexible Transparent Conducting Electrodes Based on Metal Meshes for Organic Optoelectronic Device Applications: A Review. J. Mat. Chem. C 2019, 7, 1087-1110. [CrossRef]

17. Göbelt, M.; Keding, R.; Schmitt, S.W.; Hoffmann, B.; Jäckle, S.; Latzel, M.; Radmilović, V.V.; Radmilović, V.R.; Spiecker, E.; Christiansen, S. Encapsulation of Silver Nanowire Networks by Atomic Layer Deposition for Indium-Free Transparent Electrodes. Nano Energy 2015, 16, 196-206. [CrossRef]

18. Zhu, R.; Chung, C.-H.; Cha, K.C.; Yang, W.; Zheng, Y.B.; Zhou, H.; Song, T.-B.; Chen, C.-C.; Weiss, P.S.; Li, G.; et al. Fused Silver Nanowires with Metal Oxide Nanoparticles and Organic Polymers for Highly Transparent Conductors. ACS Nano 2011, 5 , 9877-9882. [CrossRef]

19. Galagan, Y.; Rubingh, J.E.; Andriessen, R.; Fan, C.C.; Blom, P.W.; Veenstra, S.C.; Kroon, J.M. ITO-Free Flexible Organic Solar Cells with Printed Current Collecting Grids. Sol. Energy Mater. Sol. Cells 2011, 95, 1339-1343. [CrossRef]

20. Zimmermann, B.; Glatthaar, M.; Niggemann, M.; Riede, M.K.; Hinsch, A.; Gombert, A. ITO-Free Wrap through Organic Solar Cells-A Module Concept for Cost-Efficient Reel-to-Reel Production. Sol. Energy Mater. Sol. Cells 2007, 91, 374-378. [CrossRef]

21. Jacobs, D.A.; Catchpole, K.R.; Beck, F.J.; White, T.P. A Re-Evaluation of Transparent Conductor Requirements for Thin-Film Solar Cells. J. Mat. Chem. A 2016, 4, 4490-4496. [CrossRef]

22. Cravino, A.; Schilinsky, P.; Brabec, C.J. Characterization of Organic Solar Cells: The Importance of Device Layout. Adv. Funct. Mater. 2007, 17, 3906-3910. [CrossRef]

23. Rowell, M.W.; McGehee, M.D. Transparent Electrode Requirements for Thin Film Solar Cell Modules. Energy Environ. Sci. 2011, 4, 131-134. [CrossRef]

24. Feng, Q.; Wang, W.; Jiang, K.; Huang, J.; Zhang, Y.; Song, W.; Tan, R. Effect of Deposition Condition and Uv-Ozone Post-Treatment on Work Function of DC Magnetron Sputtered Azo Thin Films. J. Mater. Sci. Mater. Electron. 2012, 23, 267-272. [CrossRef]

25. Agresti, A.; Pazniak, A.; Pescetelli, S.; Di Vito, A.; Rossi, D.; Pecchia, A.; Auf der Maur, M.; Liedl, A.; Larciprete, R.; Kuznetsov, D.V.; et al. Titanium-Carbide Mxenes for Work Function and Interface Engineering in Perovskite Solar Cells. Nat. Mater. 2019, 18, 1228-1234. [CrossRef] [PubMed] 
26. Mohanraj, J.; Stihl, M.; Simon, E.; von Sicard, O.; Schmidt, G.; Fleischer, M.; Neuber, C.; Thelakkat, M. Li-Salt-Free, Coevaporated $\mathrm{Cu}$ (TFSI) 2 -Doped Hole Conductors for Efficient $\mathrm{CH}_{3} \mathrm{NH}_{3} \mathrm{PbI}_{3}$ Perovskite Solar Cells. ACS Appl. Energy Mater. 2019, 2, $3469-3478$. [CrossRef]

27. Tao, C.; Neutzner, S.; Colella, L.; Marras, S.; Srimath Kandada, A.R.; Gandini, M.; Bastiani, M.D.; Pace, G.; Manna, L.; Caironi, M.; et al. 17.6\% Stabilized Efficiency in Low-Temperature Processed Planar Perovskite Solar Cells. Energy Environ. Sci. 2015, 8, 2365-2370. [CrossRef]

28. Stolterfoht, M.; Wolff, C.M.; Márquez, J.A.; Zhang, S.; Hages, C.J.; Rothhardt, D.; Albrecht, S.; Burn, P.L.; Meredith, P.; Unold, T.; et al. Visualization and Suppression of Interfacial Recombination for High-Efficiency Large-Area p-i-n Perovskite Solar Cells. Nat. Energy 2018, 3, 847-854. [CrossRef] 